\title{
Psychopathological Course Typology in Schizophrenia Spectrum Disorders: A Heuristic Approach in a Sample of 100 Patients
}

\author{
Moritz E. Wigand ${ }^{a}$ Fabian U. Lang ${ }^{a}$ Thomas Becker ${ }^{a}$ Thomas G. Schulze \\ Werner Strik ${ }^{c}$ Markus Jäger ${ }^{a}$ \\ ${ }^{a}$ Department of Psychiatry and Psychotherapy II, Ulm University, Günzburg, and ${ }^{\mathrm{b}}$ Institute of Psychiatric \\ Phenomics and Genomics, LMU Munich, Munich, Germany; ' University Hospital of Psychiatry, University of Bern, \\ Bern, Switzerland
}

\section{Key Words}

Schizophrenia · Typology · Heuristic approach · Bipolar pattern · Bern Psychopathology Scale

\begin{abstract}
Background: Despite several previous attempts at subtyping schizophrenia, a typology that reflects neurobiological knowledge and reliably predicts course and outcome is lacking. We applied the system-specific concept of the Bern Psychopathology Scale (BPS) to generate a course typology based on three domains: language, affectivity, and motor behaviour. Sampling and Methods: A cohort of 100 patients with schizophrenia or schizoaffective disorders according to DSM-IV criteria underwent psychopathological assessment, and all their available medical records were retrospectively analysed on the basis of the BPS. Results: Overall, $39 \%$ of the patients showed dominant abnormalities in only one domain, $37 \%$ in two domains, and $24 \%$ in all three domains. The motor domain was affected in the majority of patients (76\%), followed by affectivity (63\%) and language (46\%). Eighty-six percent of patients showed a bipolar course pattern in at least one domain. Conclusions: In a retrospective analysis of 100 patient records we described system-specific course patterns of schizophrenia by using
\end{abstract}

a neurobiologically informed psychopathological assessment. The results showed a surprisingly high proportion of bipolar courses and a pattern of pure and mixed subtypes, which speaks for an overlap of domains with regards to psychopathological symptoms. A limitation of this heuristic and retrospective approach is that it was largely based on clinical judgement. Prospective studies with more rigorous threshold definitions are needed to clarify the neurobiological and clinical implications of the proposed reorganization of psychotic disorders.

(c) 2016 S. Karger AG, Basel

\section{Introduction}

The nosological concept of schizophrenia comprises heterogeneous courses and outcomes, and the general outcome is less favourable than that of schizoaffective and affective disorders [1]. However, the boundaries between those groups of diagnoses are all but clear, and a restrictive diagnosis of schizophrenia does not seem to predict outcome better than a more inclusive diagnosis [2]. Additionally, the uncritical use in research of modern diagnostic criteria and checklists carries the risk that diagnostic concepts that have come into general use will be reified

\section{KARGER}

E-Mail karger@karger.com

www.karger.com/psp
(C) 2016 S. Karger AG, Basel

0254-4962/16/0496-0397\$39.50/0
Moritz E. Wigand, MD

Department of Psychiatry and Psychotherapy II, Ulm University

Ludwig-Heilmeyer-Strasse 2

DE-89312 Günzburg (Germany)

E-Mail moritz.wigand@t-online.de 


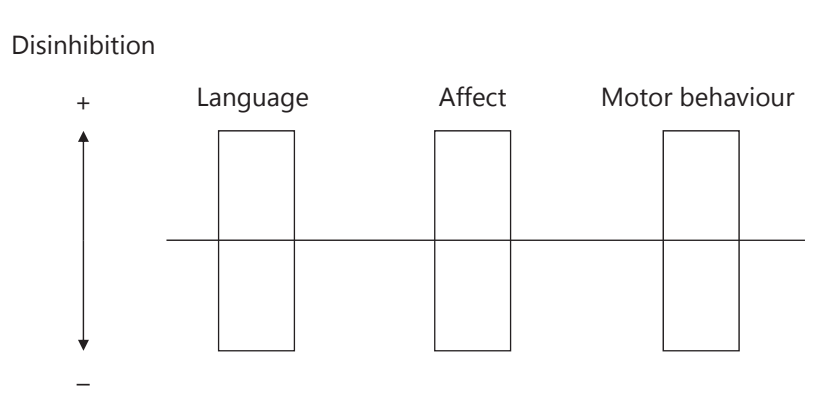

Inhibition

Fig. 1. System-specific approach as shown in Lang et al. [23].

instead of critically questioned [2] and that a reductionist view of mental phenomena will replace an in-depth, investigative, explorative, and 'modest' (self-critical) description [3-5].

Several attempts have been made to establish a course typology of schizophrenic disorders on the basis of clinical judgement [6-12]. However, such course typologies have been unable to predict treatment outcome and have not been supported by robust data from the neurobiological field, although some of them have been explicitly proposed with that aim $[10,11]$.

Recent attempts at psychopathological description went beyond the positive/negative polarity that has been in use since the 1980s $[13,14]$ and focused on a more system-specific approach. This concept traces back to the Wernicke-Kleist-Leonhard school of psychopathology. For this purpose the Bern Psychopathology Scale (BPS) was introduced by Strik et al. [15] as a research tool with a dimensional approach. The BPS offers additional information and can be seen as complementary to the Positive and Negative Syndrome Scale (PANSS) $[14,16]$. In the BPS, symptoms of schizophrenia are grouped into three domains: language, affectivity, and motor behaviour. These domains are matched to the functions of wellknown brain systems specialized in the processing of language [17-19], emotions (the limbic system) [20], and motor planning and execution $[21,22]$, respectively. Each domain is assessed in terms of a negative or positive deviation from normal function, i.e. whether it shows hypoactivity (behavioural inhibition/subjective tension) or hyperactivity (behavioural disinhibition/subjective elation) [15]. Recently, a cluster analysis identified six clusters for the system-specific approach of the BPS, consist- ing mainly of the respective inhibited and disinhibited states of the three domains. This finding supports the conceptual validity of the BPS [23] (fig. 1).

Whereas the BPS was developed primarily as a research tool for cross-sectional analysis with a dimensional approach, the present study focused on longitudinal data about the course of the disease to see whether a new typology would emerge. We performed psychopathological analyses of data from a well-described cohort of 100 patients who met DSM-IV criteria of schizophrenia or schizoaffective disorder [16], with the following aims: (i) to generate a course typology by using a system-specific approach to describe the long-term course of schizophrenia, (ii) to explore whether subtypes exist that clearly favour one of the domains or whether disturbances of these domains regularly co-occur, (iii) to explore whether symptoms show a unipolar or bipolar (inhibition/disinhibition) pattern over the course of the disease, and (iv) to assess how a system-specific typology relates to pre-existing typological concepts.

\section{Methods}

\section{Sampling}

The sample has been described elsewhere [16] and is part of the so-called 'DGPPN Cohort', a national collaboration initiative of the German Association for Psychiatry, Psychotherapy and Psychosomatics (DGPPN) to establish a large-scale cohort of psychiatric patients [24]. In short, the sample comprised 43 women and 57 men with a mean age of 39.8 years. Eighty-seven participants had a diagnosis of schizophrenia and 13 of schizoaffective disorder. The mean duration of treatment at the Department of Psychiatry II, Ulm University, was 8.4 years (range $0-34$ years); 38 patients had been in treatment at the hospital for 10 years or longer. The hospital has a large rural catchment area, and all emergency admissions and most regular admissions from this area are referred to this hospital. Furthermore, patients tend to stay living in the area. For this reason, we believe that a majority of the patients' psychotic episodes were treated at this hospital. The mean age at first admission was 30.6 years (SD 10.9 years; men 30.0 years, women 30.7 years). Many patients had had symptoms well before first admission and had been treated outside the hospital by general practitioners or psychiatrists or had not received any treatment at all. The number of previous admissions to the department before recruitment into the study ranged from 0 to 56 (mean 7.1). All patients (or their legal guardians or both) provided written informed consent. The study was performed in accordance with the Declaration of Helsinki and the study protocol was approved by the local ethics committee.

\section{Assessment}

All patients were recruited as inpatients at the Department of Psychiatry II, Ulm University. They were clinically assessed, and their history was taken. The Structured Clinical Interview for DSM-IV Axis I Disorders (SCID-I) [25] was performed to confirm 
the diagnosis according to DSM-IV criteria. Cross-sectional psychopathological symptoms were assessed at study entry with a thorough free-text description according to the German psychopathology manual Arbeitsgemeinschaft für Methodik und Dokumentation in der Psychiatrie (AMDP) [26] and with the BPS [15] and PANSS [14]. The psychiatric history was taken with the lifechart model [27]. Psychopathological assessment was performed by F.U.L., who had received extensive training in the scales.

\section{Retrospective Course Typology}

To generate a psychopathological course typology, we considered all obtainable data for each case, including the admission sheets (with history of present illness given by the patient and, if present, by relatives, mention of police reports or doctors' referrals, and a thorough psychopathological description), the therapists' progress notes, and all discharge letters. Data obtained on the index admission (psychiatric history and psychopathological data) were also used.

We tested each piece of psychopathological information to examine whether it pertained to one of the three BPS domains (language, affectivity, motor behaviour) and, if so, whether it showed inhibition or disinhibition according to the operational definitions of the BPS [15]. By combining all the above information we were able to comprehensively assess the BPS ratings of each psychotic episode. If at least one of the domains showed both polarities over the course of the observation period, the case was labelled as having a 'bipolar course pattern', which is not the same as a diagnosis of bipolar affective disorder but merely describes that we found both inhibition and disinhibition in at least one of the domains over the course of the observation period. If one domain was predominantly affected, the case was labelled a pure case. If more than one domain was affected, the case was labelled a combined case (two domains) or a mixed case (all three domains equally affected). We wrote case reports to illustrate some of the subtypes (see Results).

In addition, we applied the traditional typologies for course and outcome of schizophrenic psychoses. In accordance with Watt et al. [12], we classified the course as (i) single episode course, (ii) episodic course (with full remission between the episodes), or (iii) chronic course. Using the concepts of Gerd Huber [7, 8, 9], we divided outcome into (i) full remission, (ii) uncharacteristic residues, and (iii) characteristic residues. Finally, we classified all cases according to Karl Leonhard [10] as (i) cycloid psychoses, (ii) unsystematic schizophrenias, or (iii) systematic schizophrenias. Two psychiatrists (M.E.W. and M.J.) performed the retrospective ratings independently.

\section{Results}

\section{System-Specific Psychopathological Course Types}

Table 1 shows the pathological subtypes (bipolar or unipolar) of our patient sample according to the systemspecific approach of the BPS. The great majority of cases $(n=86)$ showed a bipolar pattern of symptoms over the course of the disease. Patients with a bipolar disease course had been in treatment longer than those with a unipolar course (9.2 vs. 5.6 years), but the difference was
Table 1. Psychopathological subtypes

\begin{tabular}{lccc}
\hline & $\begin{array}{l}\text { Unipolar } \\
\text { course, } \mathrm{n}\end{array}$ & $\begin{array}{l}\text { Bipolar } \\
\text { course, } \mathrm{n}\end{array}$ & $\begin{array}{l}\text { Total, } \\
\mathrm{n}\end{array}$ \\
\hline $\begin{array}{l}\text { Pure types } \\
\text { Language dominant }\end{array}$ & 0 & 3 & 3 \\
$\begin{array}{l}\text { Affect dominant } \\
\text { Motor dominant }\end{array}$ & 6 & 10 & 16 \\
\hline Combined and mixed types & 1 & 19 & 20 \\
Language/affect & 1 & 4 & 5 \\
Language/motor & 0 & 14 & 14 \\
Affect/motor & 2 & 16 & 18 \\
Mixed & 4 & 20 & 24 \\
\hline Total & 14 & 86 & 100 \\
\hline
\end{tabular}

not significant ( $t$ test: 0.121 ). Fourteen patients showed a unipolar pattern of symptoms, and 13 of those 14 patients showed abnormalities in the affectivity domain, all of which were towards the inhibited pole. The polarity of language and motor symptoms was not as uniform and varied from case to case: 2 patients showed an inhibited language domain and 3 a disinhibited language domain, and 4 patients showed an inhibited motor domain and 3 a disinhibited motor domain.

The motor domain was found to be affected in the majority of cases $(n=76)$, followed by the affectivity $(n=63)$ and language $(n=46)$ domains. Only 39 cases were rated as pure types, 37 showed a combination of two domains ('combined types') and 24 showed a mixture of all three domains ('mixed types'). Among the pure types, the motor-dominant cases were highest in number $(n=20)$, whereas only very few cases were language dominant $(\mathrm{n}=3)$. Among the combined types, the combination of language and affectivity was rare $(n=5)$, whereas symptoms in the motor domain were frequently associated with the language domain $(n=14)$ and the affectivity domain $(\mathrm{n}=18)$. Age and duration of treatment did not show any significant correlations with the domains affected or with the number of domains affected (data not shown).

All patients with schizoaffective disorder $(n=13)$ showed a bipolar symptom pattern. Three of the cases were pure (motor dominant $\mathrm{n}=2$; affect dominant $\mathrm{n}=1$ ), 4 were mixed types, and 6 were combined types.

\section{Case Reports}

To exemplify our qualitative approach, we present three case reports that show different aspects of our typology. Cases 1 and 2 are examples of a bipolar course, 
the most common in our sample, and case 3 reflects a unipolar course. Cases 2 and 3 show pure types that exhibit psychopathological symptoms in one prominent domain, whereas case 1 shows a mixed type in which all three domains are affected. Note that also the 'pure types' contain psychopathological symptoms in domains other than the predominant one, but these symptoms were less intense and less frequent. In case 2, symptoms from the motor domain were always present and exhibited both quantitative (hyper- and hypoactivity) and qualitative fluctuations (mannerisms, bizarre gait disorder). These symptoms are mentioned frequently in the medical records and are the primary target of treatment. On the other hand, although formal thought disorder and fearful affect are mentioned, they do not show the same intensity or frequency as the symptoms from the motor domain.

\section{Case Report 1: Mixed Bipolar Subtype}

Mrs. S. is a 52-year-old woman. She was first diagnosed with schizophrenia at age 19 , when she was brought to our psychiatric service by the local police. On first admission, she showed severely incoherent speech, reported hearing a voice of undetermined sex, and had religious delusions. Her affect was fearful and dysphoric, and her psychomotor activity was at first highly excited with aggressive behaviour against staff; on the following day she developed a catatonic stupor. After receiving first-generation antipsychotics and occupational therapy, she was discharged in an improved condition to continue her apprenticeship as a dental assistant. She never finished her apprenticeship, and in the following years was repeatedly readmitted with a range of symptoms in all three domains, including psychomotor inhibition and excitement, feelings of fear and depression and feelings of grandiosity (being Jesus, being the centre of the world) and love, and disinhibited and inhibited speech. For the past 1.5 years, she has been stable on clozapine, living alone, adequately caring for her household and two cats, living on an invalidity pension because of her schizophrenia, and seeing a psychiatrist at least every 3 months. She is slightly fearful but has no detectible delusions or disorders of perception. She shows a minor disturbance of concentration and some social withdrawal.

\section{Case Report 2: Bipolar Motor-Dominant Subtype}

Mrs. K. is a 48-year-old woman. Her first hospital admission and diagnosis of schizophrenia was at age 30, although she had already been seeing a psychiatrist for 3 years because of unusual behaviour such as taking long walks at night, from which she was sometimes brought home by the police, and (often repetitive) actions that did not seem to make sense. On first admission, she showed a formal thought disorder, delusions, a fearful affect, and reduced psychomotor activity with mannerisms, so that even simple activities of daily living such as changing clothes became difficult. In the hospital, she developed a gait disorder that faintly looked like a spastic paresis of the right leg but without any neurological finding; the gait disorder improved with clozapine and worsened when the dose of clozapine was reduced. On second admission (via emergency room) she showed a remarkably reduced motor activity and lack of drive, her speech was slow and somewhat circumstantial, and her affect blunted. Although she seemed suspicious, no delusions or disorders of perceptions could be detected on admission. She showed a loss of hand extension on the right side, probably due to radial nerve palsy after lying on a park bench (without any detectible influence of alcohol or drugs, more likely in a catatonic stupor). On the third and fourth admissions, both in a psychotic state, she showed increased motor activity: before the third admission, she had been picked up by police in a park where she had been seen roaming around. When included in this study, she showed reduced motor activity and a loss of drive.

\section{Case Report 3: Unipolar Affect-Dominant Subtype}

Mr. S. is a 40-year-old man. His first hospital admission and diagnosis of schizophrenia was at age 26 . He grew up with his grandmother because his mother also has schizophrenia. He was brought into psychiatric treatment by the police, who had been called by the patient's grandmother after Mr. S. had locked himself into his room with several knives and threatened to kill everybody entering his room. He was suspicious and frightened and reported that he felt threatened and persecuted. Later on he reported having a microphone implanted in his throat which was used for eavesdropping and which also emitted sounds and voices. His language was somewhat inhibited and his drive reduced. He had had some suicidal thoughts, saying he wanted to kill himself before being killed by those who persecuted him. He was discharged in a better condition after 2.5 months but was repeatedly readmitted in the following years, always with delusions of persecution and delusions of influence, paired with fright and suspiciousness. The motor domain (loss of drive) and language domain (inhibited language) were also slightly affected, but in the 14 years of medical records we examined no domain ever changed polarity. 
Table 2. Unipolar subtypes compared to traditional concepts

\begin{tabular}{|c|c|c|c|}
\hline & Watt et al. [12] & Huber [7-9] & Leonhard [10] \\
\hline \multicolumn{4}{|l|}{ Pure types } \\
\hline Language dominant & $(\mathrm{n}=0)$ & $(\mathrm{n}=0)$ & $(\mathrm{n}=0)$ \\
\hline Motor dominant & chronic $(\mathrm{n}=1)$ & uncharacteristic residuum $(\mathrm{n}=1)$ & systematic schizophrenia $(\mathrm{n}=1)$ \\
\hline Language/motor & $(\mathrm{n}=0)$ & $(\mathrm{n}=0)$ & $(\mathrm{n}=0)$ \\
\hline Affect/motor & chronic $(\mathrm{n}=2)$ & characteristic residues $(\mathrm{n}=2)$ & $\begin{array}{l}\text { unsystematic schizophrenia }(\mathrm{n}=1) \\
\text { systematic schizophrenia }(\mathrm{n}=1)\end{array}$ \\
\hline \multirow[t]{2}{*}{ Mixed } & single episode $(n=1)$ & full remission $(n=1)$ & cycloid psychosis $(\mathrm{n}=1)$ \\
\hline & chronic $(\mathrm{n}=3)$ & uncharacteristic residues $(\mathrm{n}=3)$ & systematic schizophrenia $(\mathrm{n}=3)$ \\
\hline
\end{tabular}

\section{Association with Traditional Course Typologies}

Because our concept is built on pre-existing typologies, we looked for overlaps with similar and different concepts. According to the concept of Watt et al. [12], the great majority $(n=80)$ of our sample showed chronic impairment (stable or increasing); 13 had an episodic course and 7 a single episode. According to the concept of Huber [7, 8, 9], 20 patients were in full remission, 27 showed uncharacteristic residues, and 53 showed characteristic residues. Finally, according to Leonhard's classification [10], 52 of the cases were unsystematic schizophrenias, 28 systematic schizophrenias, and 20 cycloid psychoses (tables 2, 3).

We compared our typology with pre-existing concepts and found that most unipolar types fell into Leonhard's category of systematic schizophrenias (12/14) and most bipolar types fell into the categories of cycloid psychoses or unsystematic schizophrenias (69/84). Although most unipolar types showed residual states according to Huber and chronic states according to Watt, the outcome of the bipolar group was more heterogeneous.

\section{Discussion}

Impact of a System-Specific Typology

The results of our longitudinal retrospective psychopathological analyses show the following:

1 The BPS, a cross-sectional psychopathological instrument, can also be applied in a longitudinal assessment that describes course patterns of schizophrenia on the basis of three psychopathological domains (language, affectivity, and motor behaviour)

Psychopathological Course Typology
2 The majority of cases had a combined or mixed pattern involving more than one domain

3 The majority of cases showed a bipolar pattern, alternating between inhibition and disinhibition in at least one domain

4 There was a considerable overlap with Leonhard's typology

The present study used the dimensional system-specific approach of the BPS [15] to generate a longitudinal course typology of schizophrenic disorders. The idea of a typological approach traces back to the German philosopher and psychopathologist Karl Jaspers, who adopted Max Weber's sociological concept of 'ideal types' in a psychopathological context [28]. According to these considerations, each typology might be of heuristic value to reduce complexity, while the empirical 'reality' is likely to show some overlaps between categories. In fact, only $39 \%$ of cases were pure types, i.e. they affected predominantly one domain (language, affectivity, or motor behaviour), and even these cases showed some abnormalities in other domains, albeit to a lesser degree.

We found an overlap with Leonhard's system of schizophrenias [10]. He described cycloid and unsystematic schizophrenias as having a periodic and bipolar course pattern in most cases, while systematic schizophrenias show a progressive symptomatology. This is mirrored in our sample, in which most patients with cycloid and unsystematic schizophrenias according to Leonhard fell into the 'bipolar course' category and most patients with systematic schizophrenias fell into the 'unipolar course' category. In fact, our typology was inspired by the Wernicke-Kleist-Leonhard school, but in contrast 
Table 3. Bipolar subtypes compared to traditional concepts

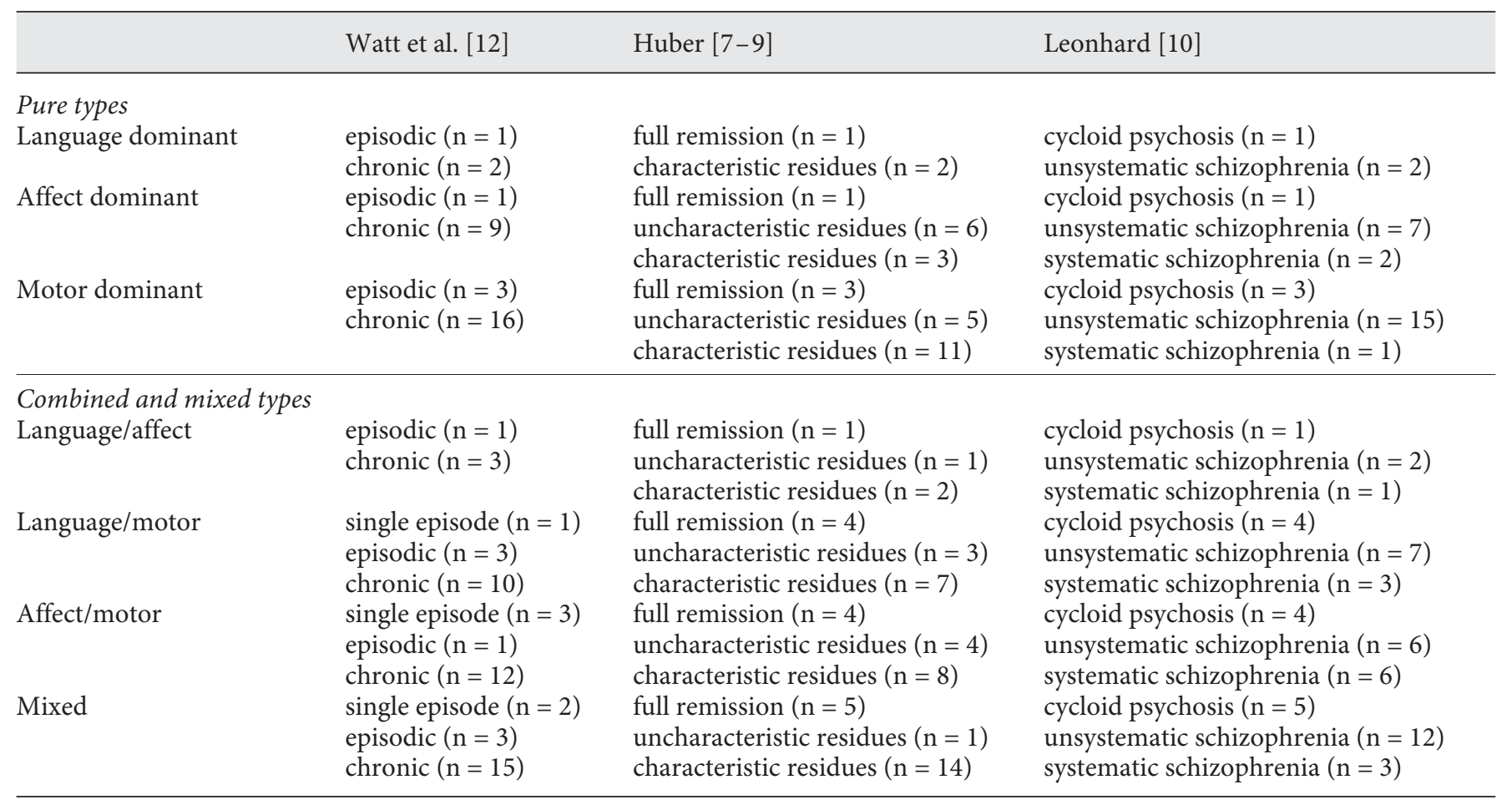

to Leonhard's sophisticated and hypothetical constructs the present typology is based on the assumption that psychopathological symptoms in schizophrenia spectrum disorders can be reliably matched to three different, wellcharacterized neurobiological systems (language system, limbic system, and motor system) [15]. It therefore intends to bridge the gap between psychopathological and neurobiological approaches. A limitation of this study is that the same psychiatrists rated the domain-specific typology and the traditional typologies, so that some sort of rater bias cannot be excluded.

Our comparison with Huber's [7-9] and Watt's [12] typologies of disease course and outcome showed that patients with a unipolar course tended to develop chronic symptoms, whereas patients with a bipolar course showed more heterogeneous outcomes. Because of the retrospective design of this study, however, such a conclusion is preliminary and needs to be tested in future prospective studies with a longitudinal approach. Nevertheless, the BPS as a cross-sectional instrument has been significantly correlated with global functioning [29], and a systemspecific approach - including the domains language [18, 19], affectivity [20] and motor behaviour [21, 22] - has been linked to meaningful neurobiological findings.
In our sample, the language domain was least affected (relative to the motor and affectivity domains) and was rarely affected in isolation. Pathologies in the language domain often showed a co-occurrence with pathologies in the motor domain. This finding has been described previously in a different sample [15]. Even though our use of the BPS allowed us to conceptualize the symptoms of its different domains as belonging to anatomically and functionally segregated brain systems which might be unequally affected by maturational deficits, we know that these brain systems are interconnected $[30,31]$. At the climax of psychosis, one brain system might then drive others into abnormal excitation, generating overlapping symptomatology. A possible approach to interpreting the high co-occurrence of motor and language symptoms could be to consider spoken language as an executive function which relies on a highly specialized part of the voluntary motor system, whereas behaviour mediated by the limbic system mainly relies on involuntary, subcortical movement patterns and the vegetative system.

\section{Bipolar Course Patterns}

Surprisingly, $86 \%$ of the patients with schizophrenia spectrum disorders showed a bipolar course in at least 
one domain. This number might even underestimate the actual incidence of bipolar courses, because patients with a unipolar course history had shorter observation periods. In any case, this result supports Leonhard's observation of bipolar symptomatology in many psychoses, in particular in cycloid psychoses and unsystematic schizophrenias [10]. However, we found bipolar patterns even in patients who were classified as systematic schizophrenias according to Leonhard's classification.

The present results raise the question of how bipolar symptom patterns are influenced by pharmacological interventions. One could hypothesize that antipsychotic medication might cause an inhibition of different neurobiological systems, with state-dependent effects. For example, neuroleptic-induced parkinsonism can be regarded as inhibition of the motor system. However, bipolar symptom patterns and motor abnormalities were already described in the pre-neuroleptic area [10], so that it is unlikely that bipolarity can be explained as a medication effect, especially because it occurs in patients who receive a stable medication regime without changes in medication or dosage. In any case, pharmacological and psychological interventions will profit from deeper insights into the nature and dynamics of individual bipolar courses of schizophrenic disorders. Finally, the question must be clarified as to how schizophrenic disorders with a bipolar course can be distinguished from bipolar affective disorders reliably and with clinical validity. Another interesting finding was that almost all patients with a unipolar course pattern showed an inhibited affectivity domain. This finding, if reproduced in further studies, should be considered in terms of neurobiological concepts and therapeutic strategies.

\section{Nosological Considerations}

On the basis of DSM-IV criteria, we identified 13 patients with schizoaffective disorders. These patients showed a bipolar course. However, a bipolar course was much more common than the diagnosis of schizoaffective disorder, and patients diagnosed with schizoaffective disorder displayed, according to our proposed system, a heterogeneous pattern of system-specific subtypes (motor-dominant, affect-dominant, combined and mixed subtypes). There are voices that challenge a nosological identity of schizoaffective disorder [32] and rather support its inclusion in a comprehensive concept of psychosis. In fact, neurobiological data suggest a strong overlap between schizophrenia and schizoaffective disorder much more than with bipolar affective disorder [33] and sociodemographic and clinical measures suggest an

Psychopathological Course Typology intermediate position of schizoaffective disorders between bipolar affective disorder with psychotic symptoms and schizophrenia [34]. A system-specific typology of psychotic disorders might have some advantages, at least for research purposes, over a diagnostic division into schizophrenia on the one hand and schizoaffective disorders on the other.

As yet, it is not possible to identify 'real' psychiatric disease entities in terms of Emil Kraepelin [35]. Nowadays, most authors favour a dimensional approach with a continuous spectrum of psychopathological symptoms. Some biomarkers seem to change over the course of the disease, which emphasizes the importance of research on psychopathological courses [36]. However, the identification of psychopathological course types within such a multi-dimensional spectrum of symptoms should be considered as a heuristic instrument. Such an instrument might be helpful for both further research activities and clinical practice. A different approach currently being discussed in the field of psychiatry [37] is that of the Research Domain Criteria (RDoC) proposed by the National Institute of Mental Health. There is a growing research matrix [38] with five domains of functioning (negative valence, positive valence, cognitive systems, systems for social processes, and arousal/regulatory systems) that tries to incorporate knowledge independent of established diagnoses, ranging from molecules to behaviour. There are overlaps between our system-specific approach and the $\mathrm{RDoC}$, for example between the negative valence system (RDoC) and the negative pole of the affectivity domain (BPS). Both are designed primarily for research activities. However, our approach is only meant as a subclassification of schizophrenic psychoses and might be seen, on a much smaller scale and only in some aspects, as complementary to the $\mathrm{RDoC}$ approach.

\section{Limitations}

The present study has several limitations. All patients were recruited as inpatients from a rural psychiatric department in Southern Germany. Consequently, the sample is not representative for two reasons: (i) inpatients usually show more severe symptoms than outpatients, and (ii) patients from only one site do not reflect geographical differences (e.g. urban vs. rural environment).

Medication affects symptoms, and most patients in our study were on medication. Because most data were collected retrospectively over a long period of time, it was not feasible to control for medication effects.

In the present study, data were obtained from one cross-sectional psychopathological examination, and lon- 
gitudinal data were assessed retrospectively. However, we included decades of well-documented case descriptions and believe that we had access to robust psychopathological data. While polarity of symptoms could be operationalized with the BPS, it was largely left to clinical judgement to rate which domains were primarily affected, after scrutinising all available psychopathological information. We did not calculate interrater reliability for this process. Threshold definitions for future prospective studies might take into account the global assessment of the BPS domains. Future, prospective longitudinal studies using a system-specific approach (and administering the BPS regularly) should test the hypotheses proposed in this paper. Such a study is currently being conducted by our group on the patient sample included in this study.

\section{Conclusion}

In the present study in a sample of 100 patients, we used a system-specific approach to subtype schizophrenia on the basis of the psychopathological domains language, affectivity, and motor behaviour. Most cases showed a bipolar course pattern in at least one of these domains. Sixty-one percent of cases showed psychopathological abnormalities in more than one domain.

\section{Acknowledgements}

This paper is based on part of a project funded by the German Research Foundation (DFG) to identify psychopathological course types of schizophrenia (JA 1742/2-1). Data were collected within the framework of the 'DGPPN Cohort', a national collaboration initiative of the German Association for Psychiatry, Psychotherapy and Psychosomatics (DGPPN). Furthermore, T.G.S. was supported by the DFG within the framework of the Clinical Research Group 241 (www.kfo241.de, grant No. SCHU1603/5-1). The authors thank Katharina Stegmayer und Sebastian Walther, both at the University Hospital of Psychiatry, University of Bern, Switzerland, for critical reading of the manuscript and their helpful comments. We also thank Jacquie Klesing, Board-certified Editor in the Life Sciences (ELS), for editing assistance with the manuscript.

\section{Disclosure Statement}

M.E. Wigand declares no conflict of interest. F.U. Lang has received remunerations and financial support for congresses from AstraZeneca, Janssen-Cilag, and Lundbeck. T. Becker reports research funding to the department (Psychiatry II, Ulm University) from Astra Zeneca, GlaxoSmithKline, and AFFECTIS Pharmaceuticals AG. The department has received funds and honoraria to a minor extent for seminars, invited speakers, and hospitality from Astra Zeneca, Bristol-Myers Squibb, Eisai, GlaxoSmithKline, Janssen Cilag, Eli Lilly, Lundbeck, Novartis, Pfizer, and Wyeth. M. Jäger declares no conflict of interest.

\section{References}

1 Lang FU, Kösters M, Lang S, Becker T, Jäger M: Psychopathological long-term outcome of schizophrenia - a review. Acta Psychiatr Scand 2013;127:173-182.

2 Jablensky A: The disease entity in psychiatry: fact or fiction? Epidemiol Psychiatr Sci 2012; 21:255-264.

3 Andreasen NC: DSM and the death of phenomenology in America: an example of unintended consequences. Schizophr Bull 2007; 33:108-112.

4 Mullen PE: A modest proposal for another phenomenological approach to psychopathology. Schizophr Bull 2007;33:113-121.

5 Nordgaard J, Parnas J: A haunting that never stops: psychiatry's problem of description. Acta Psychiatr Scand 2013;127:434-435.

6 Bleuler M: The Schizophrenic Disorders: Long-Term Patients and Family Studies (translated by Clemens SM). New Haven, Yale University Press, 1978.

7 Huber G, Gross G, Schüttler R: Schizophrenie. Verlaufs- und Sozialpsychiatrische Langzeituntersuchungen an den 1945-1959 in Bonn hospitalisierten schizophrenen Kranken. Berlin, Springer, 1979.
8 Huber G, Gross G, Schüttler R, Linz M: Longitudinal studies of schizophrenic patients. Schizophr Bull 1980;6:592-605.

9 Huber G: Psychiatrie: Lehrbuch für Studium und Weiterbildung, ed 6. Stuttgart, Schattauer, 1999.

10 Leonhard K: Classification of Endogenous Psychoses and Their Differentiated Etiology. New York, Irvington, 1979.

11 Crow TJ: Molecular pathology of schizophrenia: more than one disease process? Br Med J 1980;280:66-68.

12 Watt DC, Katz K, Shepherd M: The natural history of schizophrenia. A 5-year prospective follow-up of a representative sample of schizophrenics by means of a standardized clinical and social assessment. Psychol Med 1983; 13:663-667.

13 Andreasen NC, Olsen SO: Negative vs. positive schizophrenia. Definition and validation. Arch Gen Psychiatry 1982;39:789-794.

14 Kay SR, Fiszbein A, Opler LA: The Positive and Negative Syndrome Scale (PANSS) for schizophrenia. Schizophr Bull 1987;13:261276.
15 Strik W, Wopfner A, Horn H, Koschorke P, Razavi N, Walther S, Wirtz G: The Bern Psychopathology Scale for the assessment of system-specific psychotic symptoms. Neuropsychobiology 2010;61:197-209.

16 Lang FU, Walther S, Stegmayer K, Anderson-Schmidt H, Schulze TG, Becker T, Jäger M: Subtyping schizophrenia: a comparison of positive/negative and system-specific approaches. Compr Psychiatry 2015;61:115121.

17 Ford JM, Dierks T, Fisher DJ, Herrmann CS, Hubl D, Kindler J, Koenig T, Mathalon DH, Spencer KM, Strik W, van Lutterveld R: Neurophysiological studies of auditory verbal hallucinations. Schizophr Bull 2012;38:715-723.

18 Horn H, Federspiel A, Wirth M, Muller TJ, Wiest R, Wang JJ, Strik W: Structural and metabolic changes in language areas linked to formal thought disorder. Br J Psychiatry 2009; 194:130-138.

19 Horn H, Jann K, Federspiel A, Walther S, Wiest R, Müller T, Strik W: Semantic network disconnection in formal thought disorder. Neuropsychobiology 2012;66:14-23. 
20 Stegmayer K, Horn H, Federspiel A, Razavi N, Bracht T, Laimböck K, Strik W, Dierks T, Wiest R, Müller TJ, Walther S. Ventral striatum gray matter density reduction in patients with schizophrenia and psychotic emotional dysregulation. Neuroimage Clin 2013;4:232439.

21 Walther S, Federspiel A, Horn H, Razavi N, Wiest R, Dierks T, Strik W, Müller TJ: Resting state cerebral blood flow and objective motor activity reveal basal ganglia dysfunction in schizophrenia. Psychiatry Res 2011;31;192: 117-124.

22 Walther S, Federspiel A, Horn H, Razavi N, Wiest R, Dierks T, Strik W, Müller TJ: Alterations of white matter integrity related to motor activity in schizophrenia. Neurobiol Dis 2011;42:276-283.

23 Lang FU, Stierlin AS, Stegmayer K, Walther S, Becker T, Jäger M: Factor structure of the Bern Psychopathology Scale in a sample of patients with schizophrenia spectrum disorders. Eur Psychiatry 2015;30:880-884.

24 Anderson-Schmidt H, Adler L, Aly C, et al: The 'DGPPN-Cohort': a national collaboration initiative by the German Association for Psychiatry and Psychotherapy (DGPPN) for establishing a large-scale cohort of psychiatric patients. Eur Arch Psychiatry Clin Neurosci 2013;263:695-701.

25 First MB, Spitzer RL, Gibbon M, Williams JBW: Structured Clinical Interview for DSMIV $^{\circledR}$ Axis I Disorders (SCID-I), clinician version, administration booklet, ed 1. Arlington, American Psychiatric Association, 2012.
26 Arbeitsgemeinschaft für Methodik und Dokumentation in der Psychiatrie: Das AMDPSystem: Manual zur Dokumentation psychiatrischer Befunde, ed 8, revised. Göttingen, Hogrefe, 2007.

27 World Health Organisation: The Life Chart Schedule. Developed by Susser E, Conover S, Siegel C, and an International Team of WHO Investigators. Geneva, WHO, 1992.

28 Jäger M, Becker T, Wigand ME: The concept of typology in psychiatry in the context of historical contributions of Max Weber and Karl Jaspers (in German). Fortschr Neurol Psychiatr 2016;84:480-486.

29 Lang FU, Müller-Stierlin AS, Walther S, Schulze TG, Becker T, Jäger M: Psychopathological symptoms assessed by a system-specific approach are related to global functioning in schizophrenic disorders. Psychopathology 2016;49:77-82.

30 Obeso JA, Rodriguez-Oroz MC, Stamelou M, Bhatia KP, Burn DJ: The expanding universe of disorders of the basal ganglia. Lancet 2014; 384:523-531.

31 Catani M, Dell'acqua F, Bizzi A, Forkel SJ, Williams SC, Simmons A, Murphy DG, Thiebaut de Schotten M: Beyond cortical localization in clinico-anatomical correlation. Cortex 2012;48:1262-1287.

32 Jäger $M$, Haack $S$, Becker $T$, Frasch $K$ : Schizoaffective disorder - an ongoing challenge for psychiatric nosology. Eur Psychiatry 2011;26:159-165.
33 Amann BL, Canales-Rodríguez EJ, Madre M Radua J, Monte G, Alonso-Lana S, LandinRomero R, Moreno-Alcázar A, Bonnin CM, Sarró S, Ortiz-Gil J, Gomar JJ, Moro N, Fernandez-Corcuera P, Goikolea JM, Blanch J, Salvador R, Vieta E, McKenna PJ, PomarolClotet E: Brain structural changes in schizoaffective disorder compared to schizophrenia and bipolar disorder. Acta Psychiatr Scand 2016;133:23-33.

34 Tondo L, Vázquez GH, Baethge C, Baronessa C, Bolzani L, Koukopoulos A, Mazzarini L, Murru A, Pacchiarotti I, Pinna M, Salvatore P, Sani G, Selle V, Spalletta G, Girardi P, Tohen M, Vieta E, Baldessarini RJ: Comparison of psychotic bipolar disorder, schizoaffective disorder, and schizophrenia: an international, multisite study. Acta Psychiatr Scand 2016; 133:34-43.

35 Kraepelin E: Psychiatrie, ed 6. Leipzig, Barth, 1899.

36 Dacquino C, De Rossi P, Spalletta G: Schizophrenia and bipolar disorder: the road from similarities and clinical heterogeneity to neurobiological types. Clin Chim Acta 2015;449: 49-59.

37 Insel TR: The NIMH Research Domain Criteria (RDoC) Project: precision medicine for psychiatry. Am J Psychiatry. 2014;171:395397.

38 National Institute of Mental Health: RDoC Matrix. Bethesda, NHS, 2016. http://www. nimh.nih.gov/research-priorities/rdoc/constructs/rdoc-matrix.shtml (accessed July 20, 2016). 